\title{
Diagnosis of Macrovascular Complications in Diabetes Mellitus Using Arterial Stiffness Measured by the Cardio-Ankle Vascular Index
}

\author{
Mao Takahashi $i^{1,{ }^{*},}$ Kazuhiro Shimizu ${ }^{1}$, Takuo lizuka ${ }^{1}$, Shyuuji Satou ${ }^{1}$, Mahito Noro ${ }^{1}$, Tomoaki Shiba ${ }^{2}$ and Kohji Shirai ${ }^{3}$ \\ ${ }^{1}$ Department of Cardiovascular Center, Sakura Hospital, Medical Center, Toho University, Chiba, Japan \\ ${ }^{2}$ Department of Ophthalmology, School of Medicine, Toho University, Tokyo, Japan \\ ${ }^{3}$ Department of Vascular Function Laboratory, Sakura Hospital, Medical Center, Toho University Chiba, Japan
}

"Corresponding author: Mao Takahashi, Cardiovascular Center, Sakura Hospital, Medical Center, Toho University, Chiba, Japan, Tel: +81434628811; Fax: +81434628820; E-mail: takahashi-04@sakura.med.toho-u.ac.jp

Received date: January 02, 2017; Accepted date: January 16, 2017; Published date: January 18, 2017

Copyright: (c) 2017 Takahashi M, et al. This is an open-access article distributed under the terms of the Creative Commons Attribution License, which permits unrestricted use, distribution, and reproduction in any medium, provided the original author and source are credited.

\begin{abstract}
Arterial anti-aging treatment is important, but there had not been a good marker of arterial aging. One candidate of the markers was arterial stiffness. But, it has been difficult to measure proper arterial stiffness in vivo, noninvasively. Pulse wave velocity (PWV) which was reflecting arterial stiffness, was used for last 30 years, but was inherently changed at the blood pressure at measuring time. The cardio-ankle vascular index (CAVI) was recently developed marker reflecting arterial stiffness of the arterial tree from the origin of the aorta to the ankle. The conspicuous feature of CAVI is independency from the blood pressure at measuring time.

CAVI increased with aging both in males than in females. So, CAVI could be a good marker reflecting arterial aging. Furthermore, CAVI showed high value in most of those with various risks of coronary artery disease, and especially high in those with diabetes mellitus and even with prediabetes condition. Diabetes mellitus is kwon to be a strong factor for arterial aging. Recently, many studies showed that CAVI was improved by some of various diabetic treatments, indicating that CAVI might be an indicator of the treatment for diabetic angiopathy. Those also suggested that CAVI could be an indicator of various strategies especially controlling diabetes mellitus, in preventing, delaying vascular aging.
\end{abstract}

Keywords: Aging; Arterial stiffness; Cardiovascular risk factor; Cardio-ankle vascular index

Abbreviations: PWV: Pulse Wave Velocity; CAVI: Cardiac-ankle Vascular Index; ONH: Optic Nerve Head; Pd: Diastolic blood pressure; Ps: Systolic blood pressure; PWV: Pulse Wave Velocity.

\section{Introduction}

William Osler says that a man is as old as his arteries. In order to quantitatively measure the degree of arterial aging, arterial stiffness was proposed as an indicator from the beginning of the 20th century. From as early as 1920 pulse wave velocity (PWV) was considered to be an index which reflects the stiffness of the artery. Several methods measuring pulse wave velocity were proposed as a method for conveniently measuring arterial stiffness. But, blood pressure dependency was retained in those methods. To overcome the inherent problem in PWV, cardio-ankle vascualr index (CAVI) was presented. The cardio-ankle vascular index (CAVI), reflected the stiffness of the arterial tree from the origin of the aorta to the ankle at tibial artery. Conspicuous feature of CAVI is independency from the blood pressure at measuring time, because it was derived from the stiffness parameter $\beta$ theory, which was presented by Hayashi [1]. Stiffness parameter $\beta$ was the index reflecting arterial stiffness of a portion of the artery, and was inherently independent from blood pressure at measuirng time. Now, CAVI is widely used in the world. More than 300 papers have been reported for last ten years.
CAVI is depending on the age in both man and women, so CAVI might be a good indicator of arterial aging. Another feature of CAVI is that CAVI value is high in most of the risk factors for coronary artery diseases such as hypertension, metabolic syndrome and diabetes mellitus [2,3]. Especially, in diabetes mellitus, CAVI showed high value in diabetic retinopathy, nephropathy and macroangiopathy. So, CAVI could be an indicator of vascular aging in diabetes mellitus. Furthermore, many studies showed that CAVI was improved by some of various diabetic treatments including obesity treatment, insulin therapy, pioglitazone, and glimepiride. These results indicated that CAVI might be an possible indicator of the treatment for diabetic antipathy.

In this review, the principle of CAVI and the clinical role of CAVI in diabetic patients were presented, and discussed meanings of CAVI in controlling arterial aging with diabetic control.

\section{The Principle of CAVI and its Role in Vascular Function}

Stiffness parameter $\beta$ is an index showing the pressure required to expand the diameter of vascular wall [1]. The feature is that the pressure was shown by logarithm. Therefore, in principle, it is not influenced by blood pressure at the measuring time.

CAVI can be obtained by substituting the vascular caliber change of the stiffness parameter $\beta$ formula by the blood vessel diameter change derived from the equation of Bramwell-Hill [2,4]. 
Citation: Takahashi M, Shimizu K, lizuka T, Satou S, Noro M, et al. (2017) Diagnosis of Macrovascular Complications in Diabetes Mellitus Using Arterial Stiffness Measured by the Cardio-Ankle Vascular Index. J Aging Sci 5: 167. doi:10.4172/2329-8847.1000167

Page 2 of 5

Ps: systolic blood pressure, Pd: diastolic blood pressure, PWV: pulse wave velocity, $\Delta \mathrm{P}$ : Ps - Pd, $\rho$ : blood viscosity, constants a,b: scale conversion to match pressure corrected heart-femoral PWV.

Arterial stiffness is mainly thought to reflect the degree of arteriosclerosis, but also it reflected arterial compliance. Compliance of the artery works the second pump that catches the blood flow delivered from the heart at systolic phase, and sends it to the periphery in the diastolic phase as a vascular function. CAVI reflecting proper arterial stiffness might be also a good marker of this vascular function, in addition the role as an indicator of arteriosclerosis (Figure 1).

\section{Surrogate Marker of Arteriosclerosis}

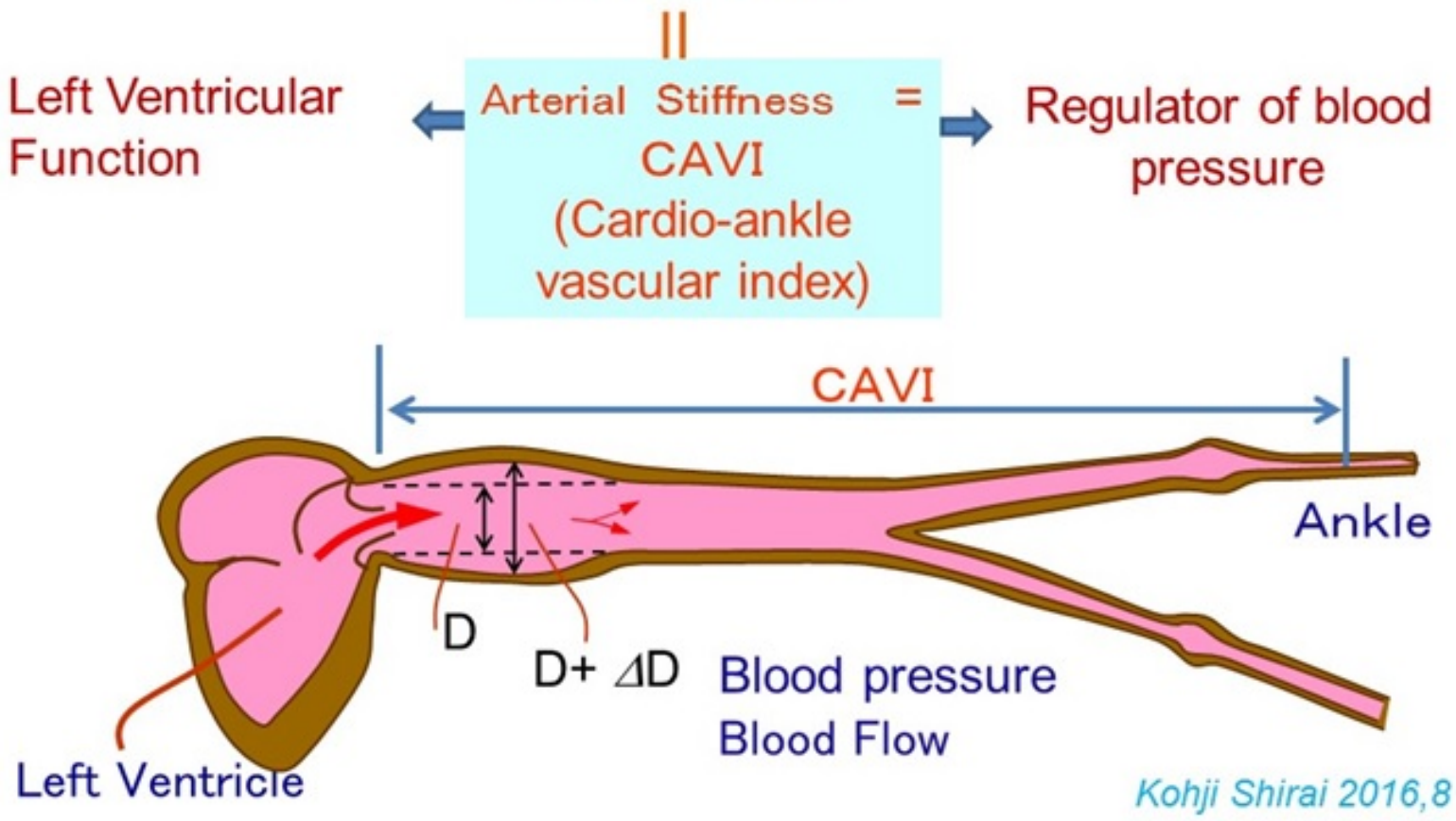

Figure 1: The role of cardio-ankle vascular index (CAVI) in vascular function.

The stiffness shown by CAVI is thought to be composed of organic stiffness and functional stiffness. Organic stiffness is composed of the matrix components (elastin, collagen, hyaluronic acid) and also smooth muscle cell of the artery. Functional stiffness is composed of contraction of smooth muscle cells. The latter was influenced by sympathetic and parasympathetic innervation. For example, the sympathetic nerve is activated when stress is applied, such as when a person is nervous or cold, the tone of the artery rises through the contraction of smooth muscle cells of the artery. Also, when parasympathetic nerves become dominant at relaxation, smooth muscle cell relaxed, then CAVI decreased (Figure 2).

When a blocking agent of the sympathetic receptor in the artery is administered, CAVI decreases [5]. In addition, with administration of the vascular smooth muscle activating substance prostaglandin $I_{2}$, CAVI is decreased as shown in Figure 3 [6]. Then, at CAVI measurement, stable conditions in concerning with a room temperature of 24 to 26 degrees, resting for about 5 minutes, and also mental relaxation were required.

\section{CAVI Values on Various Conditions, Especially in Aging, and Various Arteriosclerotic Diseases (Figure 4)}

Clinical studies have shown that CAVI increases with aging in both males and females (Figure 5), even in healthy people. This phenomena indicates that the artery might grow with increasing its vascular tone in physiological condition. But, setting the cut off value for vascular aging is controversial. Future precise analysis including pathological studies will be required. Anyway, CAVI could be a good marker of vascular aging.

Many studies indicated that CAVI was high in hypertension, metabolic syndrome, lipid abnormalities, smoking as shown in Figure 4.

Furthermore, the relationship of this vascular function with cardiac function, and also with peripheral circulation could be evaluated using CAVI $[7,8]$. 
Citation: Takahashi M, Shimizu K, lizuka T, Satou S, Noro M, et al. (2017) Diagnosis of Macrovascular Complications in Diabetes Mellitus Using
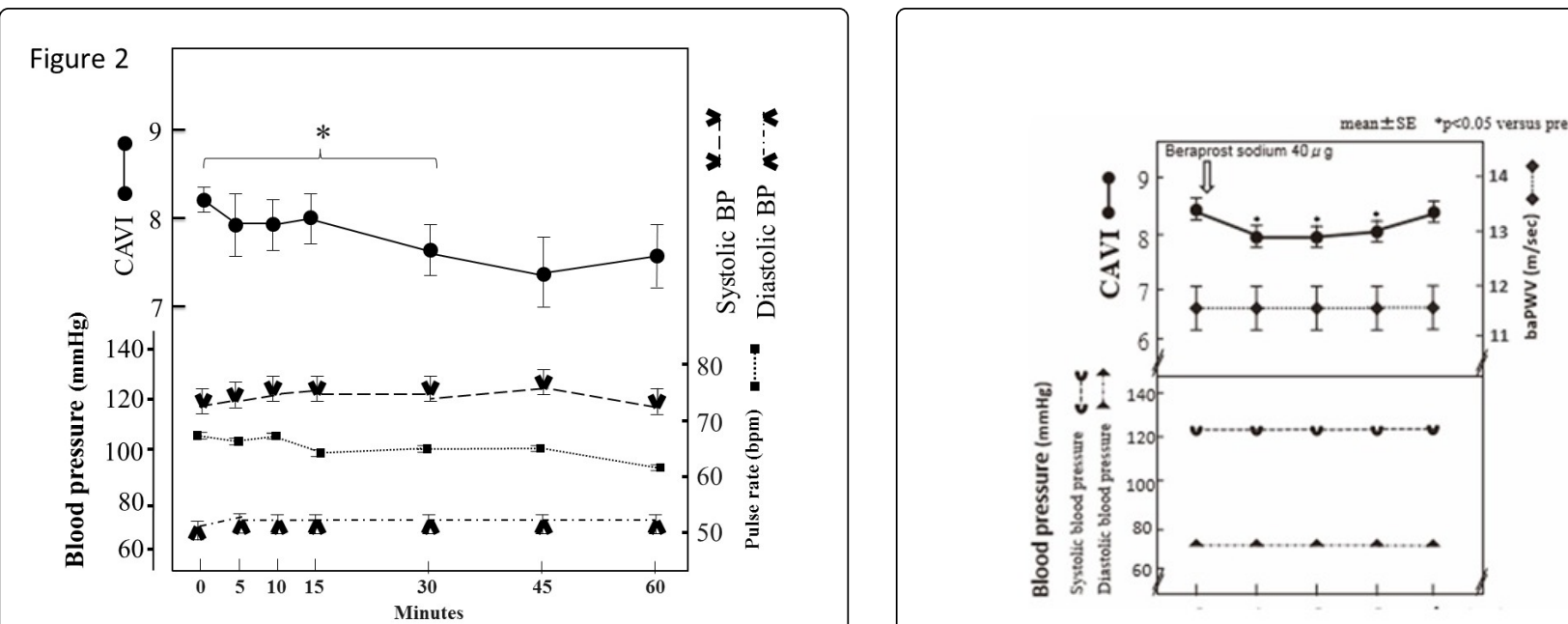

Figure 2: A case of a patient with a decrease in cardio-ankle vascular index (CAVI) due to drowsiness.

Figure 3: Decrease of cardio-ankle vascular index (CAVI) with the administration of beraprost sodium.

\section{Aging, male \\ 2. Arteriosclerotic diseases hemodialysis Cerebral infarction Coronary artery disease Chronic kidney disease}

\section{Risks}

Diabetes mellitus Hypertension Dyslipidemia Obesity Metabolic syndrome

\section{Smoking \\ 5. Stress}

\section{Risk managements}

1. Body weight reduction

2. Glucose

control Insulin Glymepiride

3. Blood pressure control ARB, Ca-blocker

4. Lipid control Statin, EPA

\section{Smoking} cessation

Figure 4: Factors which increase and decrease cardio-ankle vascular index (CAVI). ARB, angiotensin receptor blocker; EPA, eicosapentaenoic acid.

\section{CAVI in Diabetic Condition and Treatments}

Diabetes mellitus is the strong promotor of vascular aging [9-11]. CAVI was shown in to be high with diabetic patients in all ages (Figure 5). Furthermore, Namekata reported that CAVI was high in pre- diabetic condition as well as diabetic condition [12]. Especially, CAVI showed high value in diabetic retinopathy, nephropathy and macroangiopathy. So, CAVI could be a good marker of vascular injury as well as vascular aging in diabetes mellitus. 
Citation: Takahashi M, Shimizu K, lizuka T, Satou S, Noro M, et al. (2017) Diagnosis of Macrovascular Complications in Diabetes Mellitus Using Arterial Stiffness Measured by the Cardio-Ankle Vascular Index. J Aging Sci 5: 167. doi:10.4172/2329-8847.1000167

Page 4 of 5

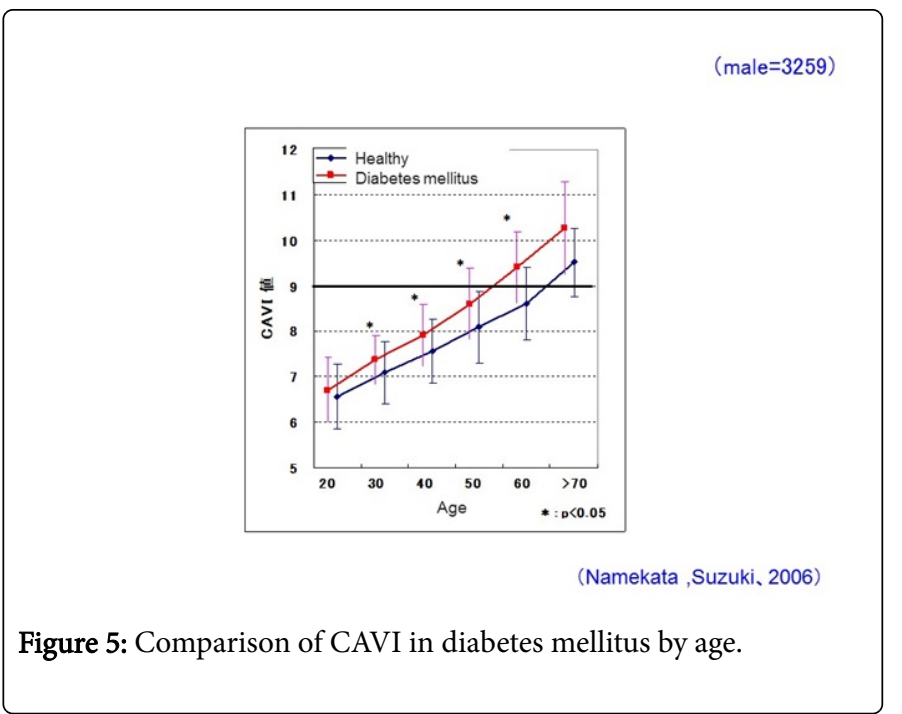

Furthermore, many studies showed that CAVI was improved by some of various diabetic treatments including obesity treatment [13], pioglitazone [14], insulin therapy [15], glimepiride [16] shown in figure 6 and dipeptidyl peptidase- 4 inhibitor. These results indicated that CAVI might be an possible indicator of the treatment for diabetic angiopathy.

On the other hand, we reported that the microvascular blood flow in optic nerve head $(\mathrm{ONH})$ can detect organ damage, such as kidney dysfunction [17], and correlates with glycosylated hemoglobin [18]. CAVI, as a macrovascular stiffness index, is related to microcirculatory blood flow in ONH [8].

These results seem to indicate that CAVI are macrovascular injury, and also microvascular injury that might be important for the function of peripheral organs.

\section{Summary}

CAVI could be a good indicator of vascular aging and also microand macro- vascular injury in diabetic mellitus. CAVI can be measured noninvasively, conveniently and at low cost. In future, medical treatment of diabetic mellitus, CAVI could be useful in evaluation of various treatments for vascular injury (Figure 6). Thus measuring CAVI might to contribute to arterial anti-aging.

\section{Disclosure}

All authors declare no conflict of interest related to this work.

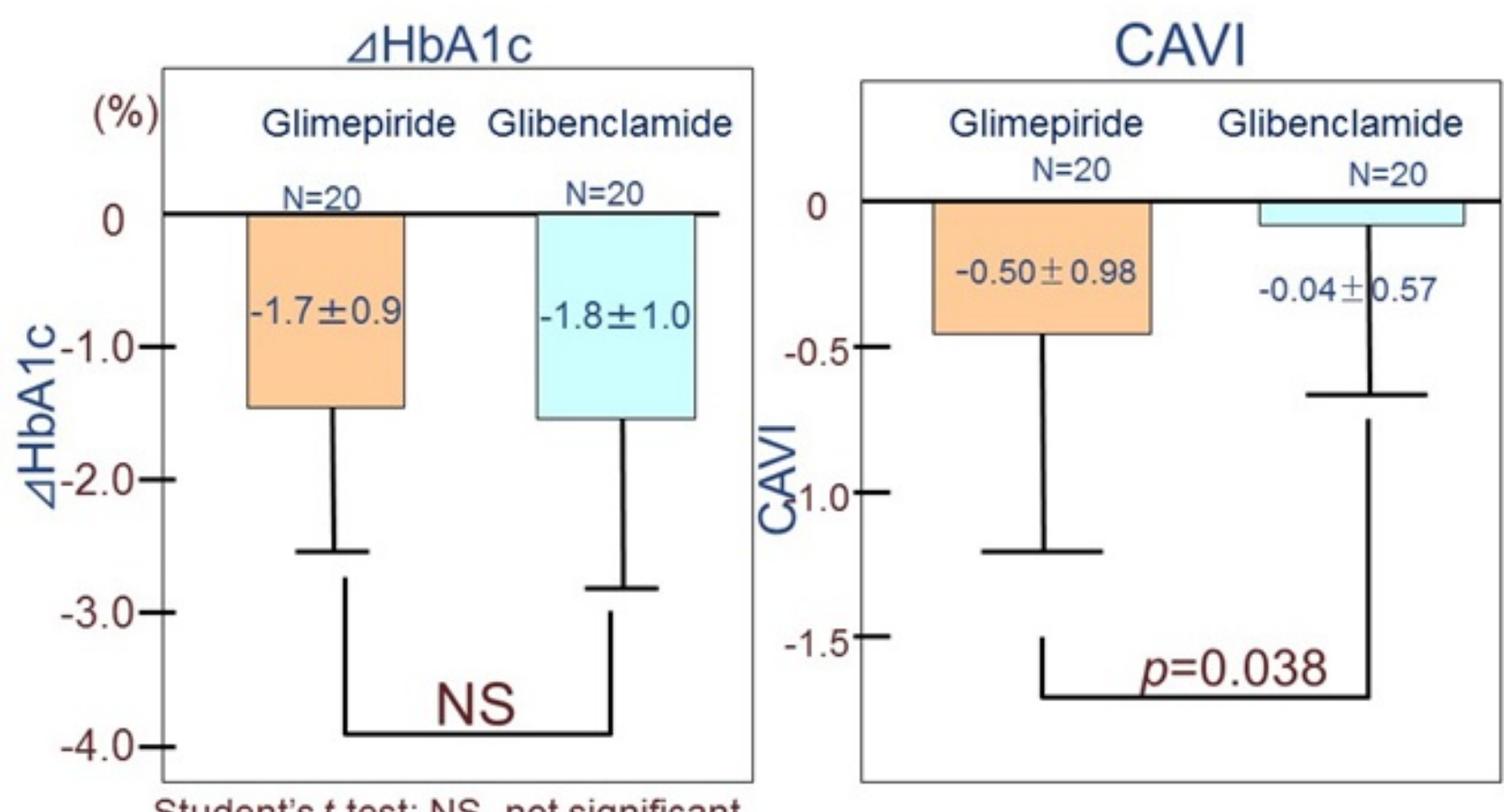

Nagayama et.al Int J Clin Pract. 2010 Oct 14. 1742-1241.

Figure 6: Improvement of cardio-ankle vascular index by glimepiride in type 2 diabetic patients. 
Citation: Takahashi M, Shimizu K, lizuka T, Satou S, Noro M, et al. (2017) Diagnosis of Macrovascular Complications in Diabetes Mellitus Using Arterial Stiffness Measured by the Cardio-Ankle Vascular Index. J Aging Sci 5: 167. doi:10.4172/2329-8847.1000167

Page 5 of 5

\section{References}

1. Hayashi K, Handa H, Nagasawa S, Okumura A, Moritake K (1980) Stiffness and elastic behavior of human intracranial and extracranial arteries. J Biomech 13: 175-184.

2. Shirai K, Utino J, Otsuka K, Takata M (2006) A novel blood pressureindependent arterial wall stiffness parameter; cardio-ankle vascular index (CAVI). J Atheroscler Thromb 13: 101-107.

3. Laurent S, Cockcroft J, Van Bortel L, Boutouyrie P, Giannattasio C, et al. (2006) Expert consensus document on arterial stiffness: methodological issues and clinical applications. Eur Heart J 27: 2588-2605.

4. Crighton Bramwell J, Hill AV (1922) The Velocity of the Pulse Wave in Man. Proceedings of the Royal Society of London 93: 298-306.

5. Shirai K, Song M, Suzuki J, Kurosu T, Oyama T, et al. (2011) Contradictory effects of $\beta 1$ - and $\alpha 1$ - aderenergic receptor blockers on cardio-ankle vascular stiffness index (CAVI) CAVI independent of blood pressure. J Atheroscler Thromb 18: 49-55.

6. Takahashi M, Shiba T, Hirano K, Hitsumoto T, Shirai K (2012) Acute decrease of cardio-ankle vascular index with the administration of beraprost sodium. J Atheroscler Thromb $19: 479-484$.

7. Zhang C, Ohira M, lizuka T, Mikamo H, Nakagami T, et al. (2013) Cardio-ankle vascular index relates to left ventricular ejection fraction in patients with heart failure. A retrospective study. Int Heart J 54: 216-221.

8. Shiba T, Takahashi M, Matsumoto T, Shirai K, Hori Y (2016) Arterial stiffness shown by the cardio-ankle vascular index is an important contributor to optic nerve head microcirculation. Graefes Arch Clin Exp Ophthalmol 255: 99-105.

9. Yamagishi S, Matsui T (2016) Pathologic role of dietary advanced glycation end products in cardiometabolic disorders, and therapeutic intervention. Nutrition. 32: 157-165.

10. Shirai K, Saiki A, Nagayama D, Tatsuno I, Shimizu K, et al. (2015) The Role of Monitoring Arterial Stiffness with Cardio-Ankle Vascular Index in the Control of Lifestyle-Related Diseases. Pulse (Basel) 3: 118-133.
11. Assar ME, Angulo J, Rodríguez-Mañas L (2016) Diabetes and ageinginduced vascular inflammation. J Physiol 594: 2125-2146.

12. Namekata T, Shirai K, Tanabe N, Miyanishi K, Nakata M, et al. (2016) Estimating the extent of subclinical arteriosclerosis of persons with prediabetes and diabetes mellitus among Japanese urban workers and their families: a cross-sectional study. BMC Cardiovasc Disord 16: 52.

13. Nagayama D, Endo K, Ohira M, Yamaguchi T, Ban N, et al. (2013) Effects of body weight reduction on cardio-ankle vascular index (CAVI). Obes Res Clin Pract 7: e139-e145.

14. Ohira M, Yamaguchi T, Saiki A, Ban N, Kawana H, et al. (2014) Pioglitazone improves the cardio-ankle vascular index in patients with type 2 diabetes mellitus treated with metformin. Diabetes Metab Syndr Obes 7: 313-319.

15. Ohira M, Endo K, Oyama T, Yamaguchi T, Ban N, et al. (2011) Improvement of postprandial hyperglycemia and arterial stiffness upon switching from premixed human insulin 30/70 to biphasic insulin aspart 30/70. Metabolism 60: 78-85

16. Nagayama D, Saiki A, Endo K, Yamaguchi T, Ban N, et al. (2010) Improvement of cardio-ankle vascular index by glimepiride in type 2 diabetic patients. Int J Clin Pract 64: 1796-1801.

17. Shiba T, Takahashi M, Maeno T (2014) Pulse-Wave Analysis of Optic Nerve Head Circulation Is Significantly Correlated with Kidney Function in Patients with and without Chronic Kidney Disease. J Ophthalmol 2014: 1-6.

18. Shiba C, Shiba T, Takahashi M, Matsumoto T, Hori Y (2016) Relationship between glycosylated hemoglobin A1c and ocular circulation by laser speckle flowgraphy in patients with/without diabetes mellitus. Graefes Arch Clin Exp Ophthalmol 254: 1801-1809. 